\title{
Massive hemoptysis due to anastomosis between the left phrenic artery and pulmonary arteries/veins
}

\begin{abstract}
Massive hemoptysis is a serious medical condition or emergency which needs immediate treatment. It typically appears in the bronchial arteries and can be caused by a wide range of pulmonary diseases. This report is based on a very rare case of a patient bleeding from an anastomosis between the left phrenic artery and pulmonary arteries/veins. In this case, the chest computed tomography had detected changes which required doctors to perform a successful embolization.
\end{abstract}

Key words: hemoptysis, phrenic artery, pulmonary artery, anastomosis, embolization

Adv Respir Med. 2020; 88: 458-461

\section{Introduction}

Hemoptysis, or the expectoration of blood, can range from the blood-streaking of sputum to the presence of gross blood in the absence of any accompanying sputum. Hemoptysis has a broad differential diagnosis, but the cause can be determined in the majority of patients [1]. Before assuming that the source of bleeding is from the lower respiratory tract, the possibility that the blood may be coming from a non-pulmonary source, such as the upper airway or the gastrointestinal tract, should be considered [2]. Hemoptysis is commonly caused by bronchiectasis, chronic bronchitis, and lung cancer [3]. Other rare causes of hemoptysis include pulmonary hamartomas, a congenital unilateral absence of the left pulmonary artery, and primary pulmonary hypertension [4]. Bronchopulmonary sequestration also can be a cause of hemoptysis.

When a patient presents with massive hemoptysis, the initial steps are to correctly position the patient, establish a patent airway, ensure adequate gas exchange and cardiovascular function, and control the bleeding [5]. Recently, non-bronchial systemic arteries have been report- ed as an important source of bleeding in patients with massive hemoptysis [6]. The Pulmonology Department of Kaunas Clinics, which is also connected to the Lithuanian University of Health Sciences, had a case where a 47-year-old male was hospitalized because of continued coughing up of blood over the course of, approximately, a few months. The diagnosed cause was both unexpected and rare.

\section{Case report}

A 47-year-old male had complained about continuing weakness, night sweats, and coughing up of blood (up to $200 \mathrm{~mL}$ per day). The patient had a history of chronic pancreatitis. He had no history of chronic bronchitis, bronchiectasis, tuberculosis, lung cancer, or other diseases. He had been smoking for roughly 30 years (approximately 10 cigarettes per day). Moreover, the man had been working as a welder for a long time. The patient reported no family history of any "lung problems".

The patient had been treated at the department of pulmonology 10 months ago. The man suffered from a low-risk pulmonary embolism,

Address for correspondence: Jolita Palacionyte, Department of Pulmonology, Hospital of Lithuanian University of Health Sciences Kauno Klinikos, Kaunas, Lithuania; 
left lung abscess, and pneumonia. The prescribed medicine was heparin (of a low molecular weight) and later, rivaroxaban, an oral factor Xa inhibitor (for a 3 month period). In addition, the patient had also received therapy in the form of antibiotics. Finally, after the stationary period, the man started coughing up a small amount of blood. This continued for about a week, but eventually disappeared. Then, 3 months ago, the coughing up of blood had returned and the patient was subsequently hospitalized in Panevezys regional hospital. An examination of the chest was carried out with the help of a computed tomography (CT) scan and it showed that the lower lobe of the left lung had changes (infiltration with air bronchograms), and the middle lobe and the basal segments of the right lung had ground-glass opacities. Furthermore, a flexible bronchoscopy showed no changes and the microscopy of the bronchial specimens showed no acid resistant sticks (ARS). Finally, Mycobacterium tuberculosis was not found to be growing in bronchial specimens. The treatment had been carried out with the help of antibiotic therapy and the anemia had been corrected with red blood cell (RBC) transfusions.

After the stationary treatment, the man continued to cough up blood over the next few months and was admitted to our hospital for the third time. During the last visit, the patient's health was normal, and his hemodynamics were also stable. The breath sound was vesicular without changes, and the breathing frequency was 16 breaths per minute. $\mathrm{SpO}_{2}$ was measured to be at 96 percent without any additional oxygen. There were no significant changes in other systems.
Based on the complaints, the disease anamnesis, and the data of the objective analysis, the patient was diagnosed with hemoptysis and chronic pancreatitis.

The blood analysis had showed anemia [hemoglobin (Hb) of $98 \mathrm{~g} / \mathrm{L}$ with a slightly increased C-reactive protein (CRP) level of $23.8 \mathrm{mg} / \mathrm{L}$ ]. Moreover, a slightly increased amount of liver enzymes [aspartate aminotransferase (AST) - $112 \mathrm{IU} / \mathrm{L}$ and alanine aminotransferase (ALT) - $39 \mathrm{IU} / \mathrm{L}]$ was also noted. The indicators of blood coagulation were within normal ranges. Finally, a fibro-bronchoscopy (FBS) was carried out because of an unclear source of bleeding from the respiratory tract. During FBS, a small amount of blood was observed in the lingula bronchus, and no active bleeding was found.

The bloody coughing continued throughout the treatment period so, therefore, a CT of the chest was performed. The chest CT revealed a heterogenous ill-defined consolidation and ground glass opacities in the lower lobe of the left lung (Figure 1). Contrast-enhanced CT showed a wide left branch of the phrenic artery and abnormal contrast enhancement in the basal segments of the left lung. These changes were considered to be anastomoses between the left phrenic artery and pulmonary arteries and veins. (Figure 2). Therefore, in order to stop the unnatural blood circulation, angiography and embolization of the left phrenic artery was performed (Figure 2).

Overall, this treatment was successful, and the symptoms were eliminated. At follow-up over one year after successful treatment, the coughing
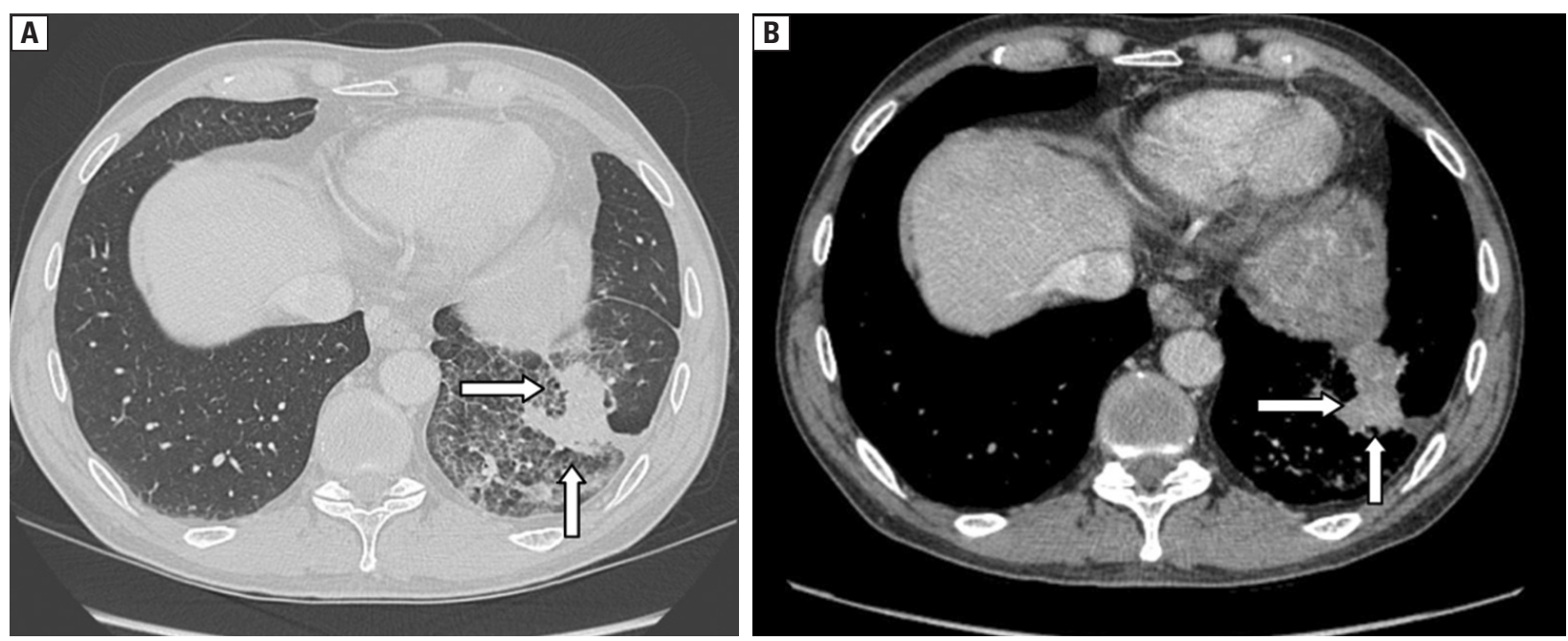

Figure 1. Computed tomography axial images demonstrate a heterogenous consolidation and ground glass opacities in the lower lobe of the left lung: A. Lung window (the lesion — white arrows); B. Soft-tissue window (the lesion — white arrows) 

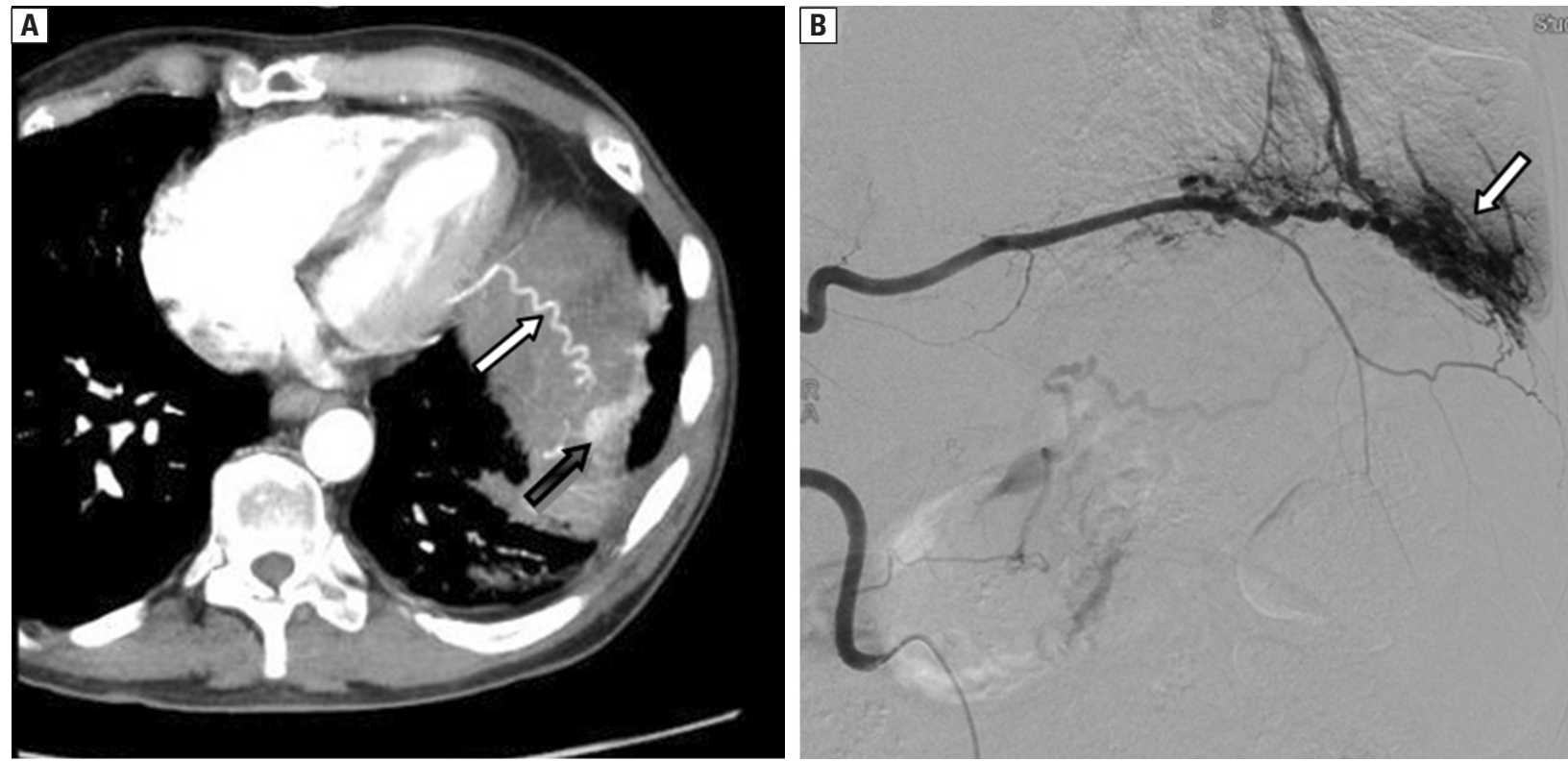

Figure 2. Contrast-enhanced computed tomography images: A. Maximum intension projection (MIP) — the white arrow shows a wide left branch of phrenic artery; the black arrow shows abnormal contrast enhancement in the basal segments of the left lung; $\mathbf{B}$. Angiography (white arrow) confirmed an abnormal vascular anastomosis between the left inferior phrenic artery and pulmonary arteries and veins

up of blood did not recur. The patient feels well and can engage in routine activities.

\section{Discussion}

This report presents a clinical case of a middle-aged male patient who had coughed up blood for a long time. However, the final diagnosis was unexpected and rare.

Blood arising from the bronchial arteries has a high perfusion pressure and as a result, is a more common source of massive hemoptysis than blood from the pulmonary circulation [7]. Less than $10 \%$ of all cases of hemoptysis originate from the pulmonary arteries [8]. In the remaining $10 \%$ of cases, the internal mammary, intercostal, and inferior phrenic artery are typically involved in hemoptysis [9]. This case of hemoptysis was caused by an anastomosis between the left phrenic artery and pulmonary arteries/veins. Transpleural systemic-pulmonary artery anastomoses may develop in patients with bronchiectasis, cystic fibrosis, tuberculosis, or chronic pneumonia [9]. In the case presented, a man had an anastomosis between the left inferior phrenic artery and pulmonary arteries and veins in the form of a fistula which was the source of bleeding in the left lower lobe. The literature describes several clinical cases of hemoptysis caused by fistula formation between the phrenic artery and pulmonary artery. Yakushiji et al. published a similar clinical case with massive hemoptysis when an elderly woman had a right inferior phrenic artery-to-pulmonary artery fistula [10].

In our case, the localization of the vascular anastomosis was the same. For this reason, we think that the left lung abscess which was detected and treated in the hospital 10 months ago was the reason this pulmonary vascular anastomosis. A left lung abscess could have caused pulmonary sequestration, which in turn would explain why the male patient presented with recurrent hemoptysis.

Pulmonary sequestration is a rare congenital malformation that is uncommonly diagnosed during adulthood [11]. Most pulmonary sequestrations arise in the left lung and receive blood supply from the systemic circulation, most commonly from the thoracic or abdominal aorta [11]. Initially, intrathoracic sequestration was thought to be a congenital anomaly and the "accessory lung bud theory" was considered to be the basis for its development [12]. Current concepts, however, suggest that it could be an acquired disease and may be attributed to obliterative bronchitis and obstruction of the lower lobe bronchus secondary to repeated necrotizing infections of the lung [12]. We think that our patients pulmonary sequestration developed after the left lung abscess. Chest CT findings are useful for the diagnosis of pulmonary sequestration as those can show cystic areas or areas of consolidation with the abnormal artery usually being mostly in the lower lobe [13]. 


\section{Conclusion}

Massive hemoptysis is a serious medical condition which needs immediate treatment. The present clinical case demonstrates that effective transcatheter embolization is a well-established and effective non-surgical procedure for the management of massive hemoptysis.

\section{Conflict of interest}

None declared.

\section{References:}

1. Weinberger SE. Etiology and evaluation of hemoptysis in adults. Available at: https://www-uptodate-com.ezproxy.dbazes.lsmuni.lt/contents/etiology-and-evaluation-of-hemoptysis-in adults? search $=$ hemoptysis\&source $=$ search_result\&selectedTitle=1 150\&usage_type $=$ default\&display_rank $=1$. [Last accessed at: 02.02.2018].

2. Ingbar DH. Massive hemoptysis: causes. Available at: www-uptodate-com.ezproxy.dbazes.lsmuni.lt/contents/massive-hemoptysis-causes?search $=$ hemoptysis\&source $=$ search result\&selectedTitle $=5 \sim 150$ \&usage type $=$ default\&display rank $=5$. [Last accessed: 02.12.2018].

3. Cordovilla R, Bollo de Miguel E, Nuñez Ares A, et al. Diagnosis and treatment of hemoptysis. Arch Bronconeumol. 2016; 52(7): 368-377, doi: 10.1016/j.arbres.2015.12.002, indexed in Pubmed: 26873518.

4. Gu W, Sun Lh, Fang Sr, et al. Clinical analysis of the rare causes of hemoptysis: a report of 4 cases. Zhonghua Jie $\mathrm{He} \mathrm{He} \mathrm{Hu} \mathrm{Xi}$ Za Zhi. 2007; 30(5): 343-346, indexed in Pubmed: 17651639.

5. Ingbar DH. Overview of massive hemoptysis. Available at: https://www-uptodate-com.ezproxy.dbazes.lsmuni.lt/contents/ /overview-of-massive-hemoptysis?search=hemoptysis\&source $=$ search result\&selectedTitle $=2 \sim 150 \&$ usage type $=$ default\&display_rank $=2$. [Last accessed at: 02.12.2018].

6. Noë GD, Jaffé SM, Molan MP. CT and CT angiography in massive haemoptysis with emphasis on pre-embolization assessment. Clin Radiol. 2011; 66(9): 869-875, doi: 10.1016/j. crad.2011.03.001, indexed in Pubmed: 21658690.

7. Grippi MA, Elias JA, Fishman JA, et al. Fishman's, pulmonary diseases and disorders. McGraw Hill, Philadelphia 2015.
8. Khalil A, Fedida B, Parrot A, et al. Severe hemoptysis: From diagnosis to embolization. Diagn Interv Imaging. 2015; 96(7-8): 775-788, doi: 10.1016/i.diii.2015.06.007, indexed in Pubmed: 26141487.

9. Webb WR, Jacobs RP. Transpleural abdominal systemic artery-pulmonary artery anastomosis in patients with chronic pulmonary infection. AJR Am J Roentgenol. 1977; 129(2): 233236, doi: 10.2214/ajr.129.2.233, indexed in Pubmed: 409155.

10. Yakushiji E, Ota S, Komatsu T, et al. Massive hemoptysis due to right inferior phrenic artery-to-right pulmonary artery fistula in the right middle lobe of the lung. Intern Med. 2017; 56(6): 687-689, doi: 10.2169/internalmedicine.56.6783, indexed in Pubmed: 28321071.

11. Petty L, Joseph A, Sanchez J. Case report: Pulmonary sequestration in an adult. Radiol Case Rep. 2018; 13(1): 21-23, doi: 10.1016/j.radcr.2017.09.029, indexed in Pubmed: 29487633.

12. Arjun P, Palangadan S, Haque A, et al. Intralobar sequestration. Lung India. 2017; 34(6): 559, doi: 10.4103/lungindia. lungindia_51_17.

13. Naoko O, Yukiyasu T, Yuko K, et al. Thoracoscopic segmentectomy for intralobar sequestration in adult: a case report. Surg Case Rep. 2018; 4: 51.

14. Lin Y, Chen Z, Yang X, et al. Bronchial and non-bronchial systemic arteries: value of multidetector CT angiography in diagnosis and angiographic embolisation feasibility analysis. J Med Imaging Radiat Oncol. 2013; 57(6): 644-651, doi: 10.1111/1754-9485.12058, indexed in Pubmed: 24283551.

15. Ghanaati H, Shakouri Rad A, Firouznia K, et al. Bronchial artery embolization in life-threatening massive hemoptysis. Iran Red Crescent Med J. 2013; 15(12): e16618, doi: $10.5812 /$ ircmj.16618, indexed in Pubmed: 24693401.

16. Walker CM, Rosado-de-Christenson ML, Martínez-Jiménez S, et al. Bronchial arteries: anatomy, function, hypertrophy, and anomalies. Radiographics. 2015; 35(1): 32-49, doi: $10.1148 /$ rg.351140089, indexed in Pubmed: 25590386.

17. Sidhu M, Wieseler K, Burdick TR, et al. Bronchial artery embolization for hemoptysis. Semin Intervent Radiol. 2008; 25(3): 310-318, doi: 10.1055/s-0028-1085931, indexed in Pubmed: 21326520 .

18. Xi Y, Liu D, Yang C, et al. [Cause of massive hemoptysis in critical patients and the effect of bronchial artery embolization]. Zhonghua Wei Zhong Bing Ji Jiu Yi Xue. 2018; 30(7): 671-676, doi: 10.3760/cma.j.issn.2095-4352.2018.07.011, indexed in Pubmed: 30045796.

19. Gu W, Sun Lh, Fang Sr, et al. [Clinical analysis of the rare causes of hemoptysis: a report of 4 cases. Zhonghua Jie $\mathrm{He}$ He Hu Xi Za Zhi. 2007; 30(5): 343-346, indexed in Pubmed: 17651639. 